Check for updates

Cite this: RSC Adv., 2018, 8, 33952

Received 22nd May 2018

Accepted 7th September 2018

DOI: $10.1039 / \mathrm{c} 8 \mathrm{ra04363a}$

rsc.li/rsc-advances

\title{
One-pot facile and mild construction of densely functionalized pyrimidines in water via consecutive $\mathrm{C}-\mathrm{C}$ and $\mathrm{C}-\mathrm{S}$ bonds formation $\uparrow$
}

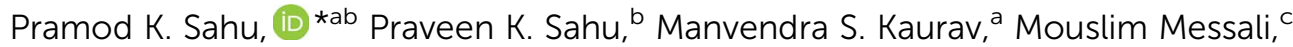 \\ Saud M. Almutairi, ${ }^{d}$ Puran L. Sahu ${ }^{e}$ and Dau D. Agarwal ${ }^{\text {ab }}$
}

Fused pyrimidines composed of alternating heteroatoms and a pyrimidine moiety were synthesized efficiently using readily available starting material 4-hydroxycoumarin, aromatic aldehydes, and urea/ thiourea at room temperature. Acid, metal salts, and surfactants were screened for their influence on catalytic activity in three-component reactions and sodium lauryl sulphate (SLS) was used as the best catalyst with different concentrations. Screening results of catalyst loading from our investigation showed that good to excellent yields were obtained with $10 \mathrm{~mol} \%$. Our method efficiently synthesized heterocycles and avoided the use of hazardous solvents and conventional organic solvents. Our procedure which involves a surfactant is operationally simple, environmentally benign, has excellent yields, short reaction times, and synthetically is as efficient as conventional procedures using organic solvents.

\section{Introduction}

The multicomponent reactions (MCRs) technique has been explored for preparation of fused pyrimidines because of their high efficiency one-pot construction instead of multi-step synthesis. Worldwide, multicomponent reactions have been explored as an efficient tool for synthesis of many active drugs. MRCs offer several advantages such as one-pot rather than multi steps for a target compound's synthesis and avoids unnecessary expensive purification, toxic reagents, and solvents. ${ }^{1-7}$ Chromenes are a promising class of heterocycles that have been explored for antioxidant, ${ }^{\mathbf{8}, 9}$ anticancer, ${ }^{10-13}$ antimicrobial, ${ }^{14-17}$ hypotensive, ${ }^{18}$ and local anesthetic activity. ${ }^{19}$ Apart from these, this class also has been explored for cognitive enhancers, ${ }^{20,21}$ Alzheimer's disease, ${ }^{22}$ and schizophrenia. ${ }^{23}$ Many plant sources having coumarin derivatives ${ }^{24}$ also have been extensively investigated as anticoagulation, antiviral, ${ }^{25}$ anti-inflammatory ${ }^{26}$ antibacterial, ${ }^{27}$ and anticancer agents. ${ }^{28}$

${ }^{a}$ School of Studies in Chemistry, Jiwaji University, Gwalior-474011, Madhya Pradesh, India.E-mail: sahu.chemistry@gmail.com; researchdata6@gmail.com

${ }^{b}$ Department of Industrial Chemistry, Jiwaji University, Gwalior-474011, Madhya Pradesh, India

${ }^{c}$ Department of Chemistry, Taibah University, 30002 Al-Madina Al-Mounawara, Saudi Arabia

${ }^{d}$ King Abdulaziz City for Science and Technology, Riyadh 11442, P. O. Box 6086, Saudi Arabia

${ }^{e}$ Indian Pharmacopoeia Commission Ministry of Health and Family Welfare, Sector-23, Raj Nagar, Ghaziabad 201002, India

$\dagger$ Electronic supplementary information (ESI) available. See DOI: 10.1039/c8ra04363a
Coumarins and their derivatives (Fig. 1A) such as warfarin, coumatetralyl, and difenacoum are used as anticoagulants whereas phenprocoumon and bromadiolone have antiviral and potent rodenticide uses, respectively. ${ }^{29}$ Carbochromen $^{30}$ is an effective coronary vasodilator. In organic and medicinal chemistry, 3,4-dihydropyrimidin-2(1H)-ones have a great place among other promising categories. ${ }^{31}$ Some drugs such as monastrol (A), ${ }^{32}$ trimethoprim $(\mathbf{B}),{ }^{33}$ and lamivudine $(\mathbf{C})^{34}$ are types of drugs with a pyrimidine core (Fig. 1B).

Finding an environmentally benign and greener approach for biologically active heterocyclic derivatives in water is a difficult task because of the green nature of water ${ }^{35}$ but, in recent years, water has been used as a diluent because of environmental consciousness. Sometimes, water could not be used as reaction medium due to insolubility of substances. But, Kobayashi et al. discovered surfactants as an option which can remove these problems $\mathrm{s}^{36}$ and that's why some surfactants show excellent catalytic activity and can be exploited as catalysts.

Considering the significance of catalytic systems and our research interests to explore novel synthesis of heterocyclic derivatives, ${ }^{37}$ we commenced our study with the synthesis of fused pyrimidines using a surfactant (SLS) in aqueous micellar form at room temperature (Scheme 1).

\section{Results and discussion}

In our initial study, we screened catalysts to find an efficient one for a model reaction of benzaldehyde, 4-hydroxy coumarin, and urea in water at room temperature (Table 1). Due to today's environmental consciousness, there is a need to develop eco- 
<smiles>CC(=O)CC(c1ccccc1)c1c(O)c2ccccc2oc1=O</smiles>

Warfarin<smiles>O=c1oc2ccccc2c(O)c1C1CCCc2ccccc21</smiles>

Coumatetralyl<smiles>CCC(c1ccccc1)c1c(O)c2ccccc2oc1=O</smiles>

Phenprocoumon<smiles>CCOC(=O)COc1ccc2c(C)c(CCN(CC)CC)c(=O)oc2c1</smiles>

Carbochromen<smiles>O=c1oc2ccccc2c(O)c1C(CC(O)c1ccc(-c2ccc(Br)cc2)cc1)c1ccccc1</smiles>

Bromadiolone<smiles>O=c1oc2ccccc2c(O)c1C1CC(c2ccc(-c3ccccc3)cc2)Cc2ccccc21</smiles>

B<smiles>CCOC(=O)C1=C(C)NC(=S)NC1c1cccc(O)c1</smiles>

Monastrol<smiles>COc1cc(Cc2cnc(N)nc2N)cc(OC)c1OC</smiles>

Trimethoprim<smiles>Nc1ccn([C@H]2CS[C@@H](CO)O2)c(=O)n1</smiles>

Lamivudine

Fig. 1 Some drugs with coumarin and pyrimidine cores.

friendly processes for chemical entities. So, we have developed a new system in water. But, organic substances often have low solubility in water which could be overcome by using surfactant emulsions with them. Initial screenings showed that SLS obtained an excellent yield (95\%) over other surfactants, as shown in Table 1, entries 6 and 7. The other catalysts used in the reaction showed poor yields, comparatively (Table 1, entries 8-11).
$p$-TSA and metal salts did not afford good yields of the desired product. An immiscible layer was formed with $p$-TSA while surfactants that possessed long alkyl chains formed colloidal dispersions. However, yield and time to complete a reaction was greatly affected by type of surfactant and catalyst's loading. Due to this concern, the reaction underwent exploration by altering the amount of catalyst $(2,5,8,10$, and $15 \mathrm{~mol} \%$ ) which afforded poor to excellent yields (33-95\%) as<smiles>[R]C1NC(CCCCC(=O)O)C([X])Nc2c1c(=O)oc1ccccc21</smiles>

$$
\begin{aligned}
& \mathrm{R}=\mathrm{C}_{6} \mathrm{H}_{5}, 2-\mathrm{OH}-\mathrm{C}_{6} \mathrm{H}_{4}, 4-\mathrm{Cl}-\mathrm{C}_{6} \mathrm{H}_{4}, 4-\mathrm{N}\left(\mathrm{CH}_{3}\right)_{2}-\mathrm{C}_{6} \mathrm{H}_{4}, 3-\mathrm{NO}_{2}-\mathrm{C}_{6} \mathrm{H}_{4}, 3-\mathrm{OCH}_{3}-4-\mathrm{OH}-\mathrm{C}_{6} \mathrm{H}_{3}, 2-\mathrm{Cl}_{-}-\mathrm{C}_{6} \mathrm{H}_{4}, 4-\mathrm{OCH}_{3}-\mathrm{C}_{6} \mathrm{H}_{4} \\
& \mathrm{X}=\mathrm{O}, \mathrm{S}
\end{aligned}
$$



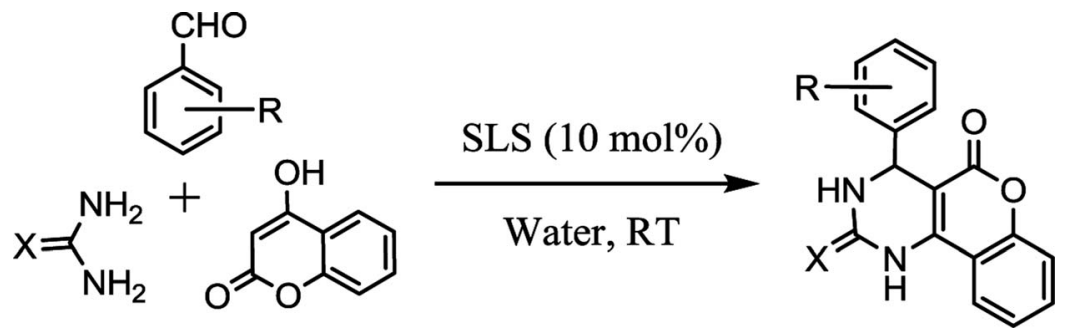

\begin{tabular}{|c|c|c|c|}
\hline Entry & Catalysts & Time (h) & Yield $^{b}(\%)$ \\
\hline 1 & SLS (2 mol\%) & 7.0 & 33 \\
\hline 2 & SLS (5 mol\%) & 6.0 & 78 \\
\hline 3 & SLS (8 mol\%) & 5.5 & 89 \\
\hline 4 & SLS (10 mol\%) & 5.0 & 95 \\
\hline 5 & SLS (15 mol\%) & 5.0 & 95 \\
\hline 6 & TBAB (10 mol\%) & 5.0 & 81 \\
\hline 7 & SDS (10 mol\%) & 5.0 & 78 \\
\hline 8 & $\mathrm{KCl}(10 \mathrm{~mol} \%)$ & 8.0 & 49 \\
\hline 9 & $\mathrm{Mg}\left(\mathrm{NO}_{3}\right)_{2}(10 \mathrm{~mol} \%)$ & 9.0 & 44 \\
\hline 10 & $p$-TSA (10 mol\%) & 8.0 & 41 \\
\hline 11 & $\operatorname{LiBr}(10 \mathrm{~mol} \%)$ & 7.5 & 71 \\
\hline
\end{tabular}

${ }^{a}$ Reaction was carried out with 4-hydroxy coumarin ( $\left.5 \mathrm{mmol}\right)$, urea $(5 \mathrm{mmol})$, and benzaldehyde $(5 \mathrm{mmol})$ at room temperature in water as solvent. ${ }^{b}$ Isolated yield.

listed in Table 1. A significant result with highest yield was obtained with $10 \mathrm{~mol} \%$ which could not be increased further with higher concentrations of catalyst. It can be concluded that $10 \%$ catalyst loading most efficiently catalyzed the reaction.

An additional investigation was carried out further to evaluate reaction time on the yield. As time increased, yield was also increased until it became constant after 5 hours which could not be further increased with increasing the reaction time. These studies showed that an optimized five hours duration was suitable for completing the reaction (Fig. 2).

To select an appropriate solvent for the reaction, we turned our attention to approaches of SLS with a number of solvents (Table 2). Optimization was undergone in different protic and aprotic solvents. As is shown in Table 2, the largest advance in the synthesis was the speed up in water among solvents used with significant outcomes which are noted and acknowledged in Table 2, entry 1 . Therefore, we have developed a new method

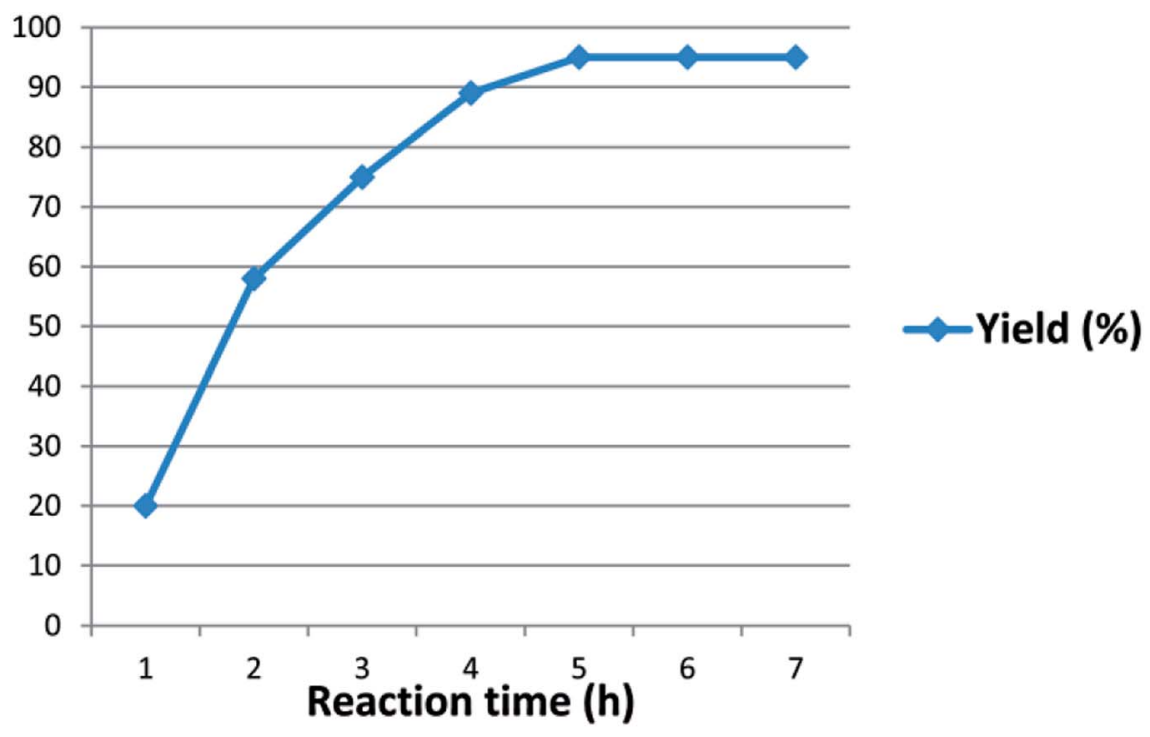

Fig. 2 Relationship between reaction time and yield. 
Table 2 Screening of solvents using SLS as catalyst ${ }^{a}$

\begin{tabular}{llcc}
\hline Entry & Solvents $(10 \mathrm{~mL})$ & Time $(\mathrm{h})$ & Yield $^{b}(\%)$ \\
\hline 1 & $\mathrm{H}_{2} \mathrm{O}$ & 5.0 & 95 \\
2 & $\mathrm{DCM}$ & 10 & 0 \\
3 & $\mathrm{MeOH}$ & 10 & 0 \\
4 & $\mathrm{EtOH}$ & 10 & 0 \\
5 & $\mathrm{ACN}$ & 10 & 0 \\
6 & $\mathrm{CHCl}_{3}$ & 10 & 0 \\
7 & Toluene & 10 & 0 \\
8 & Hexane & 10 & 0
\end{tabular}

${ }^{a}$ Reaction was carried out with 4-hydroxy coumarin (5 mmol), urea (5 $\mathrm{mmol})$, and benzaldehyde ( $5 \mathrm{mmol}$ ) in the presence of SLS (10 $\mathrm{mol} \%)$ at room temperature. ${ }^{b}$ Isolated yield.

carried out in water which is free from problems like harsh conditions and hazardous solvents.

A comparison of reported literature data and the novelty of the present methodology is provided in Table 3. As shown in Table 3 , there are few reports in the literature for synthesis of 3,4-dihydro- $1 H$-chromeno[4,3-d]pyrimidine-2,5-dione/thione derivatives using 4-hydroxycoumarin, aldehydes, and urea/ thiourea using homogeneous or heterogeneous catalysts. In order to show the merit of the present protocol, SLS catalyst was compared with other reported protocols for synthesis of pyrimidines. In contrast with other existing methods, the present methodology offers several advantages such as excellent yields, a simple and easy synthetic procedure, simple work-up rather than tedious methods, water used as a green solvent, and room temperature conditions. The results clearly show that researchers have used acids such as $\mathrm{HCl}^{\mathbf{3 8 - 4 0 , 4 2 , 4 3}}$ and chloro sulphonic acid ${ }^{38,41}$ which have drawbacks such as longer reaction times, ${ }^{38-40,42}$ harsh reaction conditions such as microwave and ultrasonication, ${ }^{39,41,43,44}$ higher temperatures $\left(60{ }^{\circ} \mathrm{C}, 110{ }^{\circ} \mathrm{C}\right.$, and reflux), hazardous solvents $(\mathrm{MeOH}, \mathrm{EtOH}$, and ACN), ${ }^{38-40,42-45}$ and often have lower yields. ${ }^{40,42-44}$ Although ultrasonication technology has been shown to be feasible on a small scale, the commercialization of sonolysis is still a challenge due to its high energy requirements which makes ultrasonication an uneconomical technique. ${ }^{46}$ On the other hand, vanadium chloride has been used as catalyst ${ }^{45}$ with lower yields, hazardous solvent (ACN), and higher temperatures. Many studies have revealed that exposure to vanadium may cause respiratory dysfunction, ${ }^{47}$ hematological and biochemical alterations, renal toxicity, ${ }^{48}$ reproductive and developmental toxicity, immunotoxicity, mutagenicity, ${ }^{49}$ and neurotoxicity. ${ }^{50}$ As seen in Table 3 , the present procedure is simpler, more efficient, without the need for toxic solvents, uses low amounts of the catalyst, and reacts at room temperature. It shows that SLS is a powerful catalyst for the synthesis of 3,4-dihydro- $1 H$-chromeno[4,3- $d]$ pyrimidine-2,5-dione/thione derivatives, suggesting that the present procedure is a clean and environmentally friendly method.

On the basis of all aforementioned experimental optimizations, we took the best reaction conditions in hand with SLS as catalyst and further explored the utility of the present methodology for substrate scope which used derived benzaldehydes to afford fused pyrimidines (4). As shown in Table 4, an electron releasing moiety led to fused pyrimidines in good yield as compared to ortho- and meta-moieties. With these reaction conditions in hand, we explored the multicomponent reaction with methyl derivatives of 4-hydroxycoumarin (4n-4q) and found smoothness of reaction with good yields, plus there was no impact of derivatization on 4-hydroxycoumarin on reaction yield or time.

To further explore the present methodology, we extended our work with guanidine in place of urea/thiourea in a three component reaction. But, the present investigation has shown that this three component reaction could not be carried out with guanidine. Biscoumarin compound $\mathbf{6}$ was observed with poor yield as the target compound instead of targeted compound 5 (Scheme 2). NMR spectra $\left({ }^{1} \mathrm{H}\right.$ and ${ }^{13} \mathrm{C}$ ) confirmed the probable structure of compound $\mathbf{6}$ which is also supported by literature. ${ }^{51}$

\section{Catalytic activity of surfactant}

Organic substrates have a hydrophobic nature which was solved by attribution of a micellar solution of surfactant as catalyst resulting in a form of emulsion droplets in water and substrate. Spherical droplets, which act as hydrophobic reaction sites and help to increase the effective accumulation of organic substrates, are responsible for immediate reactions to afford

Table 3 Comparison of present methodology with other reported catalysts

\begin{tabular}{|c|c|c|c|c|c|c|}
\hline Entry & Catalyst & Solvent & Conditions & Time $\left(\mathrm{h} \min ^{-1}\right)$ & Yield (\%) & Reference \\
\hline 1 & $\mathrm{HCl} /$ chloro sulphonic acid & $\mathrm{MeOH}$ & $60{ }^{\circ} \mathrm{C}$ & $8.0 \mathrm{~h}$ & 96 & 38 \\
\hline 2 & $\mathrm{HCl}$ & EtOH & Reflux/MW ${ }^{a}$ & $12 \mathrm{~h}$ & 94 & 39 \\
\hline 4 & Chloro sulphonic acid & - & $60{ }^{\circ} \mathrm{C} / \mathrm{US}^{b}$ & $30 \mathrm{~min}^{\circ}$ & 92 & 41 \\
\hline 5 & $\mathrm{HCl}$ & EtOH & Reflux & $12 \mathrm{~h}$ & 74 & 42 \\
\hline 6 & $\begin{array}{l}\mathrm{HCl} / \text { silica gel/acidic alumina/ } \\
\text { montmorillonite-K10 clay }\end{array}$ & $\mathrm{MeOH}$ & $110^{\circ} \mathrm{C} / \mathrm{MW}^{a}$ & $4-6 \min$ & $60 / 83 / 90 / 85$ & 43 \\
\hline 8 & $\mathrm{VCl}_{3}$ & Acetonitrile & Reflux & $2 \mathrm{~h}$ & 82 & 45 \\
\hline 8 & Sodium lauryl sulphate & Water & $\mathrm{RT}^{c}$ & $4.5 \mathrm{~h}$ & 95 & Present work \\
\hline
\end{tabular}

${ }^{a}$ Microwave conditions. ${ }^{b}$ Ultrasonication. ${ }^{c}$ Room temperature. 
Table 4 Synthesis of 3,4-dihydro-1H-chromeno[4,3-d]pyrimidine-2,5-dione/thione derivatives using SLS (10 mol\%) in water ${ }^{a}$

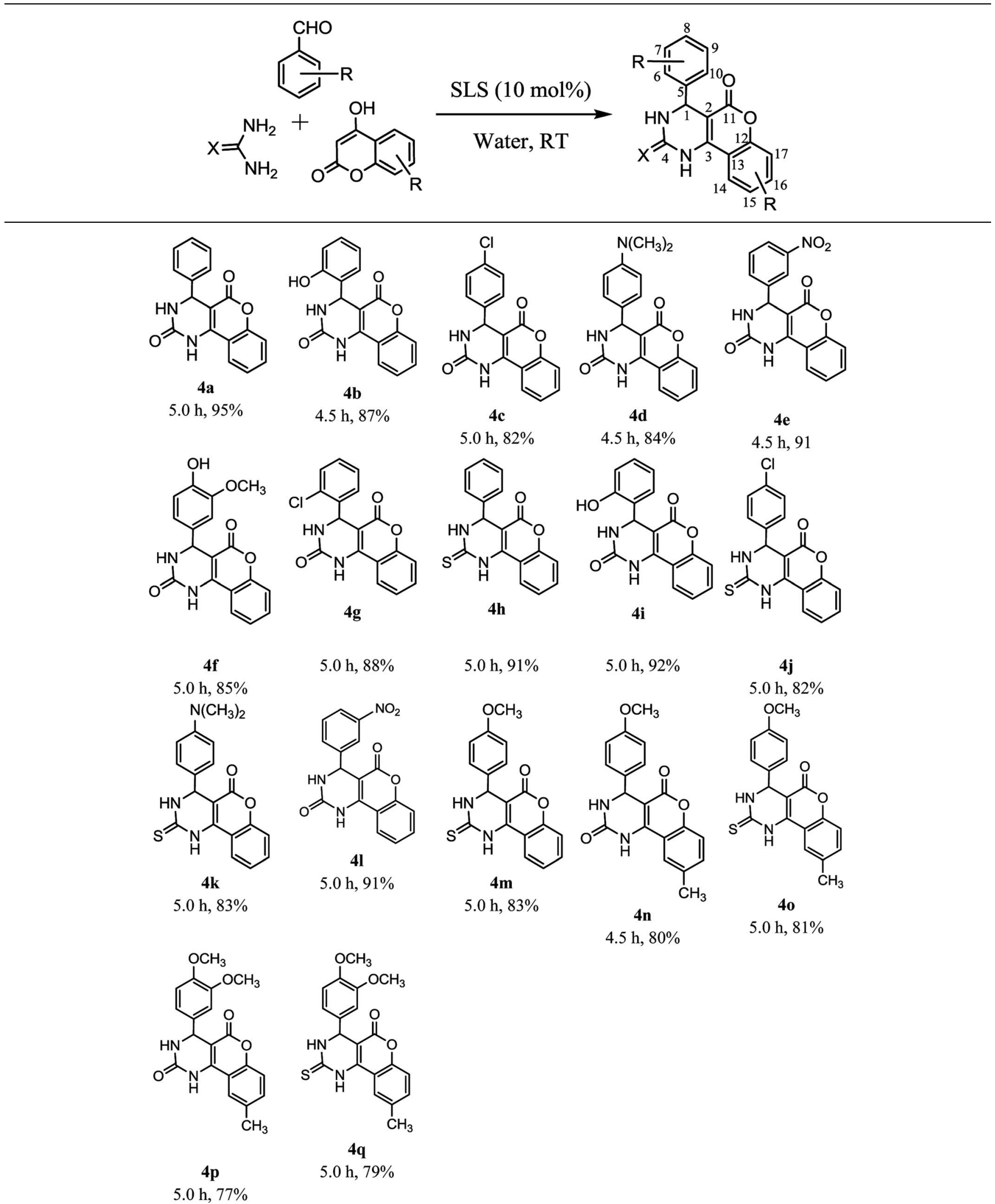

\footnotetext{
${ }^{a}$ Reaction was carried out with 4-hydroxycoumarin derivatives $(5 \mathrm{mmol})$, urea/thiourea $(5 \mathrm{mmol})$, and aromatic aldehyde $(5 \mathrm{mmol})$ at room temperature in water using SLS (10 mol\%) as catalyst.
} 
<smiles>N=C1Nc2c(c(=O)oc3ccccc23)C(c2ccccc2)N1</smiles><smiles>O=c1oc2ccccc2c(O)c1C(c1ccccc1)c1c(O)c2ccccc2oc1=O</smiles>

Scheme 2 Optimization with guanidine.

the target products in a micellar solution. It can be concluded that a micelle solution induces collision between organic substrates by pressing them together. This mechanistic pathway of a surfactant enhances catalytic activity and the resultant reaction proceeds rapidly and increases the reaction rate. $^{36,52}$

\section{Relation between action of SLS and aqueous medium}

It is believed that molecules of a surfactant generate stable colloidal particles which capture the organic substrates and surfactants attracted to the surface of the particles due to counter cations. However, substrate-replaced water molecules readily covered the sodium cation portion of surfactants. ${ }^{53}$ Equilibrium of a reaction may be shifted towards the product because water molecules, which are generated during a reaction, are easily excluded by the hydrophobic interior and result in an increase of reaction yields. ${ }^{54,55}$ Details of this phenomena are schematically represented in Scheme 3.

It is noticeable that the reaction mass, which was initially floating, was converted to a homogeneous mixture by addition of SLS, which further became a white turbid emulsion resulting in colloidal particles. Overall examination showed the arrangement of micelles which was confirmed by optical microscopy (Fig. 3). Literature also suggested our observation of the formation of spherical particles..$^{52,56-58}$

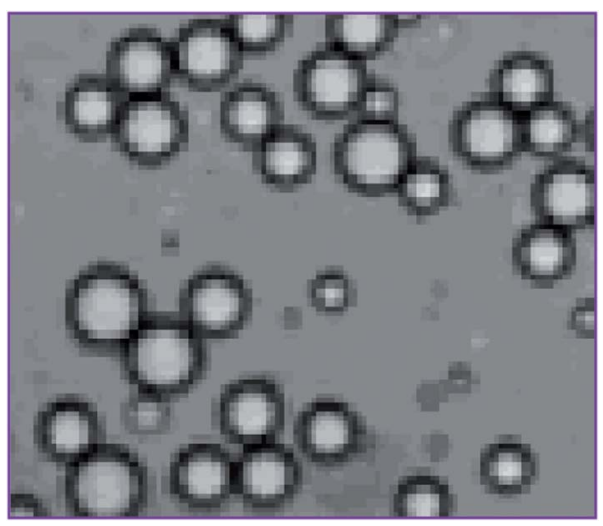

Fig. 3 Light microscopic detected micelles (scale bar $=5 \mu \mathrm{m}$ ).

\section{Mechanistic pathway}

A plausible mechanism for fused pyrimidines synthesis (4) is shown in Scheme 4. Initially, 4-hydroxycoumarin (1) and aldehyde (2) interacted each other by Knoevenagel condensation to produce an intermediate which was pursued by Michael addition of urea/thiourea (3) on the double bond of the intermediate (A) to form intermediate (B). Furthermore, the carbonyl and amino corner of the Michael adduct $\mathbf{B}$ was condensed through intramolecular cyclization to give the desired target (4).

\section{Conclusion}

We have explored a facile construction of biologically significant fused pyrimidine-2,5-dione/thione in water as green solvent at room temperature. SLS was successfully synthesized and suitable for use as a micellar catalyst and removed the problem of using an organic solvent, thus generating a green platform for future synthesis of novel molecules in water. The protocol for the synthesis of fused pyrimidine-2,5-dione/thione with different aromatic aldehydes over the present catalytic system was successfully applied with excellent yields. This method has described for the first time use of SLS as a catalyst

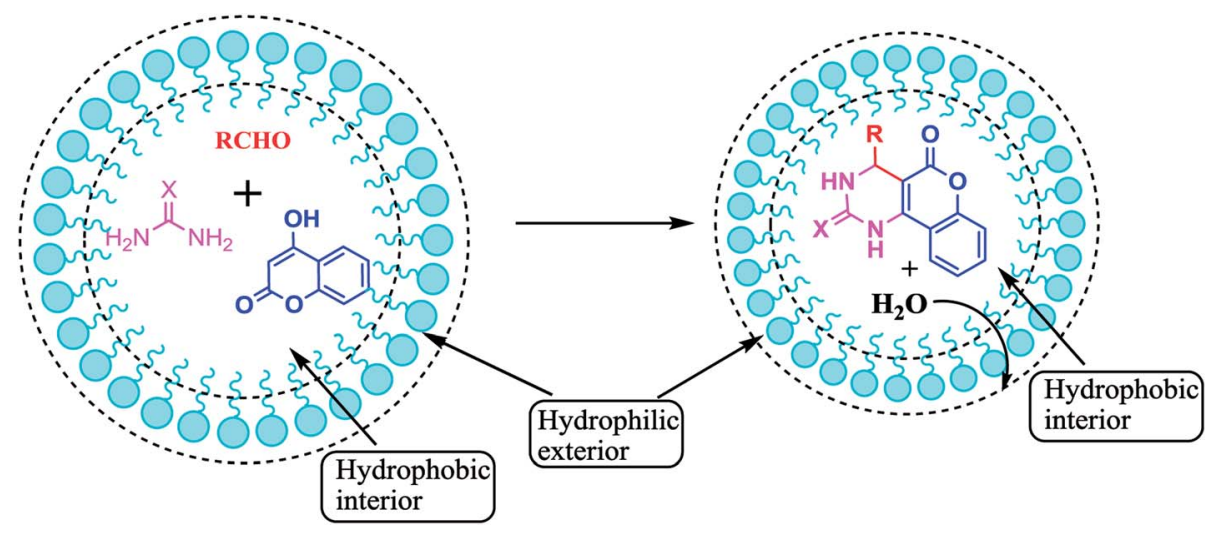

Scheme 3 Schematic diagram representing the role of SLS. 
<smiles>CC(=O)CC1C(=O)Oc2ccccc2C1O</smiles>

(1)<smiles>[R]C(O)C(CC)C1C(=O)Oc2ccc(C3C(C)C3C)cc2C1=O</smiles>

$\mathrm{H}_{2} \mathrm{O}$

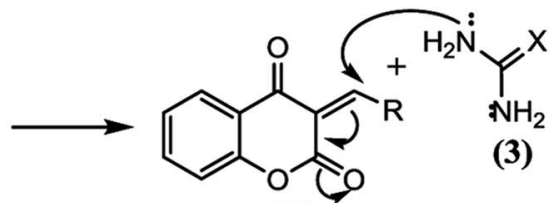

(A)

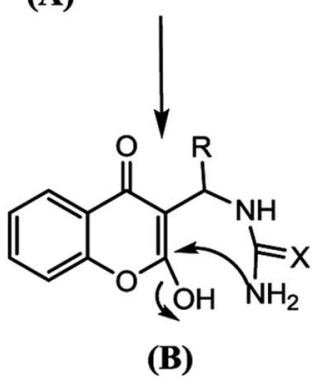

Scheme 4 A proposed mechanistic pathway for the synthesis of derivatives (4).

in the transformation of fused pyrimidines-2,5-dione/thione. As far as reactivity and selectivity are concerned, water as an inexpensive green solvent also played a vital role. Taking consideration of environmental consciousness, surfactants efficiently catalyzed the reaction at room temperature.

\section{Synthesis of fused pyrimidines-2,5-dione/thione}

Typical procedure. A three neck round-bottomed flask was charged with aldehydes (2 mmol), 4-hydroxy coumarin (2 $\mathrm{mmol})$, and urea/thiourea $(2 \mathrm{mmol})$ in water $(10 \mathrm{~mL})$. Catalyst sodium lauryl sulphate $(10 \mathrm{~mol} \%)$ was charged in the reaction mixture. Reaction was conducted at RT for a desired period of time. The reaction was monitored by TLC analysis and confirmed by spectroscopic analysis.

\section{Conflicts of interest}

There are no conflicts to declare.

\section{Acknowledgements}

We acknowledgements and humble thanks to Dr P. L. Sahu, IPC Ghaziabad, India for their valuable suggestion and spectral analytical data.

\section{References}

1 C. O. Kappe, Curr. Opin. Chem. Biol., 2002, 6, 314.

2 V. Nair, C. Rajesh, A. Vinod, U. S. Bindu, A. R. Streekenth, S. Mathen and L. Balagopal, Acc. Chem. Res., 2003, 36, 899.

3 D. J. Ramon and M. Yus, Angew. Chem., Int. Ed., 2005, 44, 1602.

4 A. A. Domling, Chem. Rev., 2006, 106, 17.

5 A. Domling and I. Ugi, Angew. Chem., 2000, 112, 3300.

6 L. F. Tietze and A. Modi, Med. Res. Rev., 2000, 20, 304.

7 J. Zhu, Eur. J. Org. Chem., 2003, 1133.

8 L. Alvey, S. Prado and V. Huteau, Bioorg. Med. Chem., 2008, 16, 8264 .
9 T. Symeonidis, M. Chamilos, J. Hadjipavlou-Litina, M. Kallitsakis and E. Litinas, Bioorg. Med. Chem. Lett., 2009, 19, 1139.

10 J. L. Wang, D. Liu and Z. J. Zhang, Proc. Natl. Acad. Sci. U. S. A., 2000, 97, 7124.

11 J. F. Cheng, A. Ishikawa, Y. Ono, T. Arrheniusa and A. Nadzana, Bioorg. Med. Chem. Lett., 2003, 13, 3647.

12 D. Grée, S. Vorin and L. Manthati, Tetrahedron Lett., 2008, 49, 3276.

13 W. Kemnitzer, S. Jiang and H. Zhang, Bioorg. Med. Chem. Lett., 2008, 18, 5571.

14 M. M. Khafagy, A. H. F. A. El-Wahas, F. A. Eid and A. M. ElAgrody, Farmaco, 2002, 57, 715.

15 M. Kidwai, S. Saxena, M. K. Rahman Khan and S. S. Thukral, Eur. J. Med. Chem., 2005, 40, 816.

16 B. S. Kumar, N. Srinivasulu and R. H. Udupi, Russ. J. Org. Chem., 2006, 42, 1813.

17 R. R. Kumar, S. Perumal, P. Senthilkumar, P. Yogeeswari and D. Sriramm, Bioorg. Med. Chem. Lett., 2007, 17, 6459.

18 V. K. Tandon, M. Vaish, S. Jain, D. S. Bhakuni and R. C. Srimal, Indian J. Pharm. Sci., 1991, 53, 22.

19 M. Longobardi, A. Bargagna, E. Mariani, P. Schenone and E. Marmo, Farmaco, 1990, 45, 399.

20 H. Bedair, A. El-Hady, S. Abd El-Latif, H. Fakery and M. ElAgrody, Farmaco, 2000, 55, 708.

21 M. M. Heravi, K. Bakhtiari, V. Zadsirjan and F. Bamoharram, Bioorg. Med. Chem. Lett., 2007, 17, 4262.

22 C. Bruhlmann, F. Ooms and P. Carrupt, J. Med. Chem., 2001, 44, 3195.

23 S. R. Kesten, T. G. Heffner and S. J. Johnson, J. Med. Chem., 1991, 42, 3718.

24 R. Kumar, S. Malik and R. Chamdra, Indian J. Chem., 2009, 48B, 718.

25 J. Kempson, W. J. Pitts, J. Barbosa, J. Guo, O. Omotoso, A. Watson, K. Stebbins, G. C. Starling, J. H. Dodd, J. C. Barrish, R. Felix and K. Fischer, Bioorg. Med. Chem. Lett., 2005, 15, 1829. 
26 O. Bruno, C. Brullo, S. Schenone, F. Bondavalli, A. Ranise, M. Tognolini, M. Impicciatore, V. Ballabeni and E. Barocelli, Bioorg. Med. Chem., 2006, 14, 121.

27 A. V. Ivachtchenko, E. S. Golovina, M. G. Kadieva, A. G. Koryakova, S. M. Kovalenko, O. D. Mitkin, I. M. Okun, I. M. Ravnyeyko, S. E. Tkachenko and O. V. Zaremba, Bioorg. Med. Chem., 2010, 18, 5282.

28 S. A. Said, A. E.-G. Amr, N. M. Sabry and M. M. Abdalla, Eur. J. Med. Chem., 2009, 44, 4787.

29 (a) T. Mizuno, I. Nishiguchi, T. Hirashima, A. Ogawa, N. Kambe and N. Sonoda, Synthesis, 1988, 257; (b) A. Clerici and O. Porta, Synthesis, 1993, 99.

30 V. B. Fiedler and J. Scholtholt, J. Pharmacol. Exp. Ther., 1981, 217, 306.

31 L. Alvey, S. Prado and V. Huteau, Rasayan J. Chem., 2009, 2, 662.

32 T. U. Mayer, T. M. Kapoor, S. J. Haggarty, R. W. King, S. L. Schreiber and T. J. Mitchison, Science, 1999, 286, 971.

33 J. Clayden, N. Greeves, S. Warren and P. Wother, Organic chemistry, Oxford University Press, 2006, p. 1180.

34 S. L. Gaonkar and H. Shimizu, Tetrahedron, 2010, 66, 3314.

35 (a) ACS Symposium Series, Green Chemistry, ed. P. T. Anastas and T. C. Williamson, American Chemical Society, Washington, DC, 1996, vol. 626; (b) P. Anastas and J. C. Warner, Green Chemistry: Theory and Practice, Oxford University Press, Oxford, 1998.

36 (a) S. Kobayashi, K. Manabe and S. Nagayama, Modern Carbonyl Chemistry, ed. J. Otera, Wiley-VCH, Weinheim, 2000; (b) K. Manabe, Y. Mori, T. Wakabayashi, S. Nagayama and S. Kobayashi, J. Am. Chem. Soc., 2000, 122, 7202; (c) S. Kobayashi, S. Nagayama and T. Busujima, J. Am. Chem. Soc., 1998, 120, 8287.

37 (a) P. K. Sahu, P. K. Sahu, Y. Sharma and D. D. Agarwal, J. Heterocycl. Chem., 2014, 51, 1193; (b) P. K. Sahu, P. K. Sahu, S. K. Gupta, D. Thavaselvam and D. D. Agarwal, Eur. J. Med. Chem., 2012, 54, 366; (c) P. K. Sahu, P. K. Sahu, D. Thavaselvam, A. M. Alafeefy and D. D. Agarwal, Med. Chem. Res., 2015, 24, 725; (d) P. K. Sahu, P. K. Sahu, S. K. Gupta and D. D. Agarwal, Catal. Sci. Technol., 2013, 3, 1520; (e) P. K. Sahu, P. K. Sahu, S. K. Gupta and D. D. Agarwal, Ind. Eng. Chem. Res., 2014, 53, 2085; (f) P. K. Sahu, P. K. Sahu, R. Jain, R. Yadav and D. D. Agarwal, Catal. Sci. Technol., 2012, 2, 2465.
38 D. Bhut, R. Gami, A. Parikh, C. Sharma and P. Patel, Pharma Sci. Monit., 2015, 6, 149.

39 M. Kidwai, S. Saxena and R. Mohan, Russ. J. Org. Chem., 2006, 42, 52.

40 D. I. Brahmbhatt, G. B. Raolji, S. U. Pandya and U. R. Pandya, Indian J. Chem., 1999, 38(B), 839.

41 M. A. Abdulkarim Al-Kadasi and G. M. Nazeruddin, J. Chem. Pharm. Res., 2013, 5, 204.

42 P. K. Ambre, R. R. S. Pissurlenkar, R. D. Wavhale, M. S. Shaikh, V. M. Khedkar, B. Wan, S. G. Franzblau and E. C. Coutinho, Med. Chem. Res., 2014, 23, 2564.

43 M. Kidwai and P. Sapra, Synth. Commun., 2002, 32, 1639.

44 M. Kidwai and S. R. Priya, Z. Naturforsch., 2008, 63b, 71.

45 G. Sabitha, G. S. K. K. Reddy, K. B. Reddy and J. S. Yadav, Tetrahedron Lett., 2003, 44, 6497.

46 J. C. Crittenden, R. R. Trussell and D. W. Hand, Water Treatment Principle and Design, G. Tchobanglouse, John Wily and Sons, 2nd edn, 2004.

47 M. A. Woodin, Y. Liu, D. N. R. Hauser, T. J. Smith, et al., Am. J. Ind. Med., 2000, 37, 353.

$48 \mathrm{H}$. Zaporowska, W. Wasilewski and M. Slotwińska, BioMetals, 1993, 6, 3.

49 M. R. Avila-Costa, E. Montiel Flores, L. Colin-Barenque, J. L. Ordoñez, A. L. Gutiérrez, et al., Neurochem. Res., 2004, 29, 1365.

50 H. Li, D. Zhou, Q. Zhang, C. Feng, W. Zheng, et al., NeuroToxicology, 2013, 36, 49.

51 (a) H. Banari, H. Kiyani and A. Pourali, Res. Chem. Intermed., 2017, 43, 1635; (b) S. Qadir, A. A. Dar and K. Z. Khan, Synth. Commun., 2008, 38, 3490.

52 L. M. Wang, N. Jiao, J. Qui, J. J. Yu, J. Q. Liu, F. L. Guo and Y. Liu, Tetrahedron, 2010, 1, 339.

53 H. Firouzabadi, N. Iranpoor and A. Garzan, Adv. Synth. Catal., 2005, 347, 1925.

54 Y. Watanabe, K. Sawada and M. Hayashi, Green Chem., 2010, $12,384$.

55 D. Rideout and R. Breslow, J. Am. Chem. Soc., 1980, 102, 7816, (CA. 94: 46413).

56 L. M. Wang, N. Jiao, J. Qiu, J. J. Yu, J. Q. Liu, F. L. Guo and Y. Liu, Tetrahedron, 2001, 57, 2537.

57 Y. Moroi, N. Nishikido, H. Uehara and R. Matuura, J. Colloid Interface Sci., 1975, 50, 254.

58 A. Chatterjee, K. H. Sandip, M. Banerjee and P. K. Bhattacharya, Tetrahedron Lett., 2010, 51, 6700. 